\title{
CASTEAUR: A tool for operational assessments of radioactive nuclides transfers in river ecosystems
}

\author{
P. Boyer and K. Beaugelin-Seiller
}

Institute for Protection and Nuclear Safety, DPRE/SERLAB, Laboratory of Environmental Modelling, CE Cadarache, bâtiment 159, BP. 1, 13108 Saint-Paul-lez-Durance cedex, France

\begin{abstract}
CASTEAUR (french acronym for Simplified CAlculation of radioactive nuclides Transfer in Receiving WATERways) is an operational tool to assess the impact on fluvial ecosystems of both accidental and routine radioactive releases. This code is organised over a simplified representation of the hydrographic network, on which simplification was applied to the five domains : hydraulics, sedimentary dynamics, ecology and radioecology. The ecosystem could be described by six components which are water, suspended and settled matters, primary producers, first order consumers and fish. According to time and space and with the possibility to take into account four kinds of radioactive releases, from pulse to continuous pollution, CASTEAUR assesses the radioactive nuclides concentrations in these components. These concepts are formalised in a prototype, which offers the possibility to combine the different kind of releases, pollutants and ecosystem components. This paper presents these concepts (hypothesis, models and functionalities) and some application example.
\end{abstract}

\section{INTRODUCTION}

CASTEAUR is a code dedicated to the operational assessment of the radioecological impact on fluvial ecosystems. Using conventional and validated models, its originality is the offer of a single tool to treat crisis and routine situations, linking the main abiotic and biotic components of the river. These components are for the abiotic part water and matters, suspended as well as deposited, and for the biotic aspect phytoplankton, zooplankton, macrobenthos and fish, divided in plancktonivorous and omnivorous. To solve the radioecological transfers related to these components, it is necessary to characterise the functioning of the hydrosystem. Therefore CASTEAUR includes four other simplified models, related to one of the following sciences, necessarily involved: hydrographic, hydraulics, sedimentology and ecology. In the prototype developed under Visual Basic for Excel, users can choose between five options, which allow to treat different components sets and to adapt the calculation capacities to the considered situation (data availability and calculation time). They can use four kind of pollutant sources, each of them being composed of several radioactive nuclides and located everywhere on the river.

\section{RIVER FUNCTIONING MODELS}

One-dimensional, the general approach limits the validity domain to the good mixing area.

Hydrographic model

The river is described by a succession of reaches, constituting a hydrographic network. Each reach represents a homogeneous part of the river, for all its characteristics. It is defined by its length, $L_{r}(m)$, its slope, $I_{r}\left(m \cdot m^{-1}\right)$ and an isosceles trapezium bathymetric section form [1].

\section{Hydraulics model}

The flow conditions are supposed fluvial and permanent. The hydraulics model applied the Manning Strickler relations, using the flow, the average velocity, the Strickler coefficient and the geometrical 
parameters, such as the hydraulics radius and the wet cross section, which are deduced from the water column height, the bottom width and the bank angle of each reach [2].

\section{Sedimentary model}

Under hypothesis of permanent conditions, the matter dynamics are mathematically formulated as a function of the (suspended and deposited) matters concentrations, the global longitudinal diffusion coefficient and the rate of deposit. Only the first layer of the bottom sediment is represented by the deposited matters, because they are considered similar to the suspended one. A single kind of matter is considered per run, mineral or phytoplanktonic. Considering that the cohesive matters (diameter $<64$ $\mathrm{mm}$ ) are more reactive with radioactive nuclides [3], the deposit rate is determined by the relation of Krone [4], taken into account the settling velocity, the deposit critical shear stress of the matter and the flow shear stress.

\section{Ecological model}

Three trophic levels are considered [5]: plankton (both zoo- and phyto-), macrobenthos and fish. Mainly pelagic, the food chain is linked to the superficial bottom sediment through the macrobenthos. From it to fish, the trophic net is linear. Indeed, a realistic choice conduces to divide the fish compartment into juveniles and adults, whose diet includes the three inferior links of the food chain. The case of the phytoplankton is particular, as it is modeled as suspended matters. At each trophic level, the biological relations quantify the exchange rates of an average individual with the other levels and with the environment (alimentation, ingestion, filtration). Theoretically, these physiological parameters are space and time dependent. In a way consistent with the physical approach, they are taken to be constant per reach, and the temporal validity of CASTEAUR is thus limited to a season.

\section{RADIOECOLOGICAL MODELS}

To respond to the operational constraints induced by the situations of routine and/or crisis (data and parameter availability, calculation time delay,...), CASTEAUR allows to choose between five radioecological models associated to different hydrosystem compositions.

\section{"Raw water" option}

This choice conduces to assess the total volumic activity in water taken as a single component, including suspended matter and taking into account dispersion and radioactive decay.

\section{"Water + suspended matter" option}

Considering dispersion, exchanges between dissolved and solid phases and radioactive decay, this model assesses the dissolved and the fixed activities in the water column.

"Water + suspended matter + adult fish" option

Based on the previous selection for the abiotic components, this option adds the fish compartment, through the transfer from dissolved phase to adults.

\section{"Water + suspended matter + deposited matter" option}

This choice takes into account water, suspended and deposited matters contamination, assessing the transfers by dispersion, exchange (between dissolved and solid phases) and deposition (of the suspended matters).

\section{"Water + suspended matter + deposited matter + food chain" option}

This last alternative is the most complete of CASTEAUR. It includes the previous approach for the abiotic components and adds the transfers in the simplified food chain, considering for fish physiological parameters as dietary, growth and alimentation rates. The accumulation and depuration constants are deduced from first order kinetics. 


\section{KIND OF RELEASES}

The prototype proposes four kinds of radioactive releases, which can be composed from several radioactive nuclides, combined and distributed on the hydrographical network.

\section{Punctual permanent release}

This is a punctual release characterised by a permanent emission flow $\left(\mathrm{Bq} \cdot \mathrm{s}^{-1}\right)$. The mathematical resolution is applied for the permanent condition and gives directly the equilibrium state of the watercourse.

\section{Punctual pulse release}

This release corresponds to an instantaneous punctual addition of activity $(\mathrm{Bq})$ at a given time.

\section{Punctual sequential release}

A punctual sequential release corresponds to a punctual addition for which the emission flow $\left(\mathrm{Bq} \cdot \mathrm{s}^{-1}\right)$ can change during a period, defined by its beginning and its end.

\section{Linear sequential release}

Like the previous, this kind of release is associated to a temporal addition, which can change on a period. The difference is that it can be spatially distributed, along a part of a river $\left(\mathrm{Bq} \cdot \mathrm{s}^{-1} \cdot \mathrm{m}^{-1}\right)$, to allow admitting an eventual contribution of the basin by runoff process or an eventual atmospheric deposit.

\section{APPLICATION EXAMPLE}

The impact study prior to the establishment of a new nuclear power plant in France includes the determination of the good mixing area of its future liquid releases, for different water conditions. Usually, the employed method consists of simulating, by means of a tracer, the potential behaviour of the radioactive nuclides. This technique was applied to the Vienne River, in relation with the location of the previous release point of the Civaux plant. The concentration of rhodamine, the used tracer, was followed up in time for low and average water conditions [6], giving two chronological sets of data. It was interesting to verify if an adjustment of the model parameters enable the reproduction with a good agreement the measured concentrations. To complete this illustration, the third option of the code was used, to integrate the biotic aspect. But, as rhodamine exchange kinetics are not available for fish, the aim of the calculation is only a demonstration of the kind of results furnished. So, it was supposed that the quality of pollutant is radiocobalt, whoses radioecological parameters are well known [7].

\section{Parameters of the calculation}

The study area is described by a single $10 \mathrm{~km}$ long reach. No suspended matters are involved. The direct transfer of ${ }^{60} \mathrm{Co}$ dissolved in water is the single pathway taken into consideration for fish (accumulation kinetics: $0.154 \mathrm{ml} . \mathrm{g}^{-1} \cdot \mathrm{d}^{-1}$; depuration kinetics: $0.0372 \mathrm{~d}^{-1}$ ). The tracer input is a punctual sequential release and the hydraulics data depends on the water conditions. There assessments are obtained by adjustment on the experimental data and results. They are summarised in the table 1.

Table 1: Assessment parameters depending on water conditions

\begin{tabular}{|c|c|c|c|c|c|}
\hline & \multicolumn{3}{|c|}{ Hydraulics } & \multicolumn{2}{|c|}{ Release } \\
\hline $\begin{array}{c}\text { Water } \\
\text { conditions }\end{array}$ & $\begin{array}{l}\text { Flow } \\
\left(\mathrm{m}^{3} \cdot \mathrm{s}^{-1}\right)\end{array}$ & $\begin{array}{l}\text { Average speed } \\
\qquad\left(\mathrm{m} \cdot \mathrm{s}^{-1}\right)\end{array}$ & $\begin{array}{l}\text { Diffusion } \\
\text { coefficient } \\
\left(\mathrm{m}^{2} \cdot \mathrm{s}^{-1}\right)\end{array}$ & $\begin{array}{l}\text { Duration } \\
\text { (h) }\end{array}$ & $\begin{array}{c}\text { Flow } \\
\left(\mathrm{ppb} . \mathrm{s}^{-1}\right)\end{array}$ \\
\hline Low & 27 & 0,34 & 21 & 5,58 & $10^{-3}$ \\
\hline Average & 100 & 0,75 & 50 & 4,75 & $3,1110^{-4}$ \\
\hline
\end{tabular}




\section{Calculation results}

For the two water conditions, the code was run during a $15 \mathrm{~h}$ period after the beginning of the release, at a distance of $7000 \mathrm{~m}$ from the tracer injection point. The corresponding results, rhodamine concentration in water and theoretical ${ }^{60} \mathrm{Co}$ massic activity in fish, are exposed on figure 1 for the low water condition and figure 2 for the average water conditions.

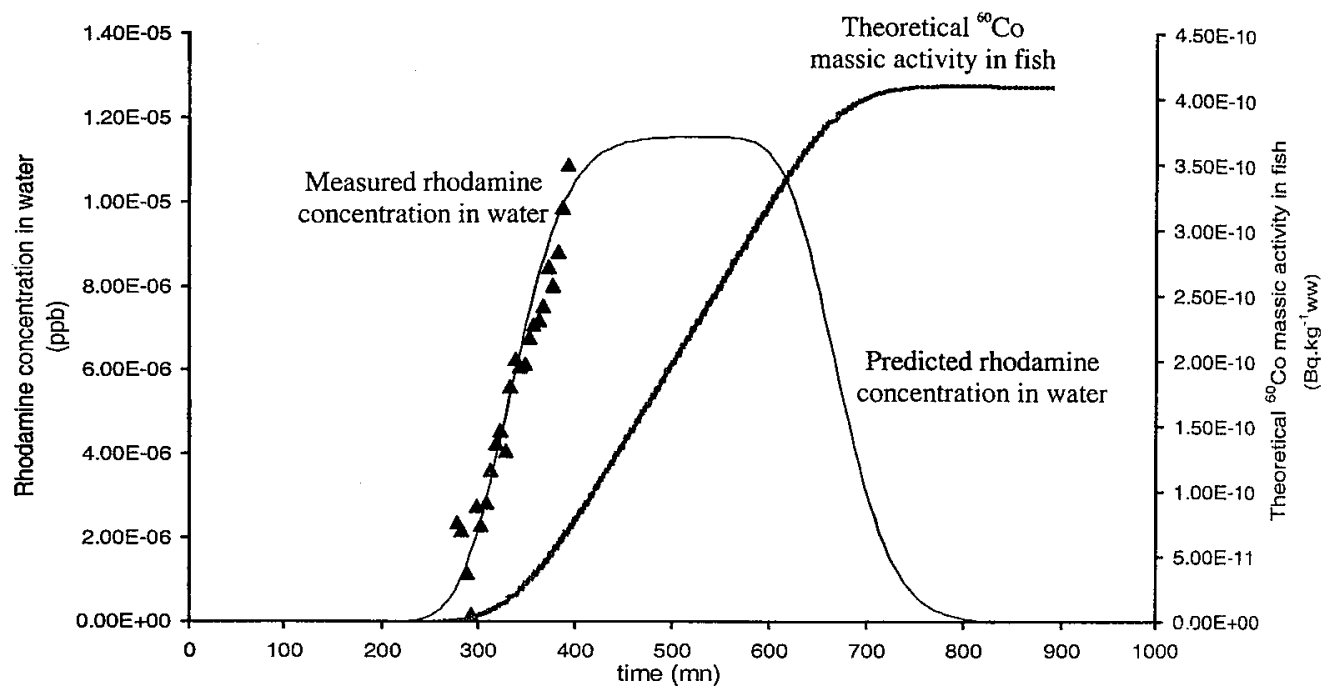

Figure 1: Comparison between predicted and measured rhodamine concentration in water and assessment of the theortical corresponding ${ }^{60} \mathrm{Co}$ massic activity in fish for low water condition.

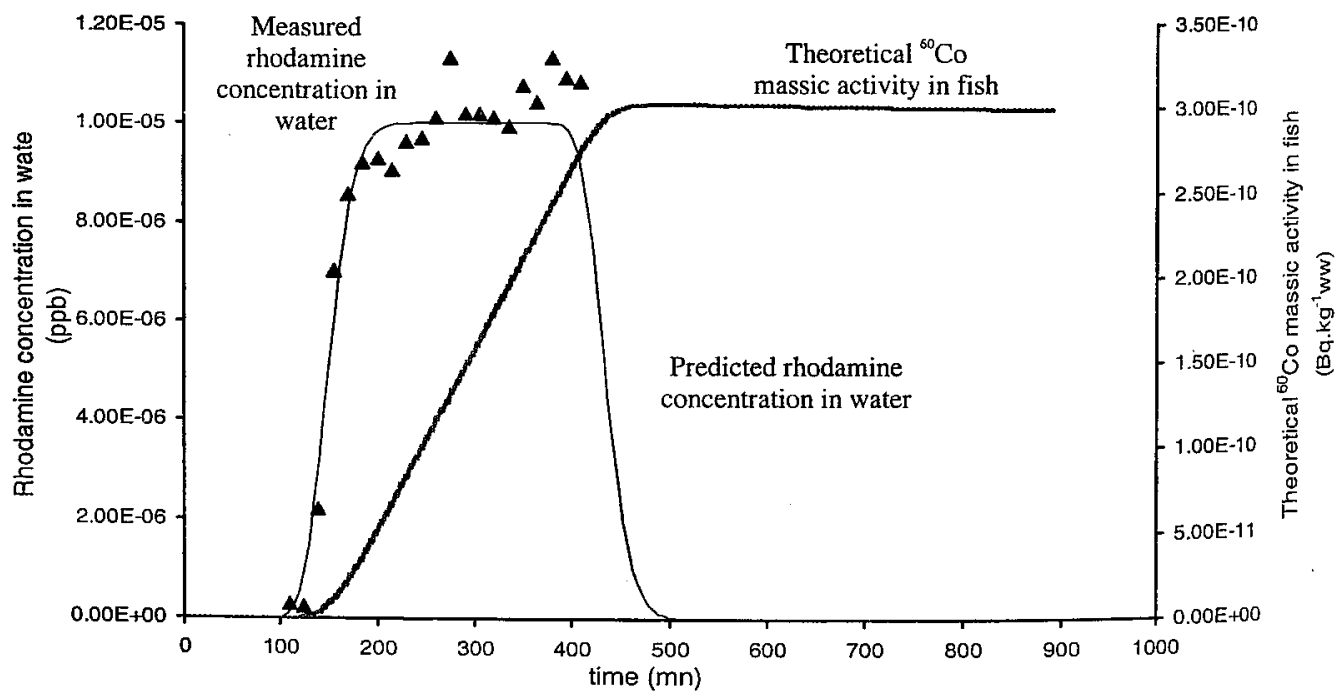

Figure 2: Comparison between predicted and measured rhodamine concentration in water and assessment of the theoretical corresponding ${ }^{60} \mathrm{Co}$ massic activity in fish for average water condition. 
The water response is all the more intense, but more delayed in time, than the flow is slow. Moreover, the chart's form, including a level section, indicates that the permanent conditions are reached. The appearance of the fish response is close but does not show the plate, as it begins to decrease as soon as the maximal value is reached, due to slow kinetics versus release duration.

Predicted values versus measurements

The predictions made for the low water condition are in very good agreement with the measurements, most of them being on the assessment curve. The agreement is less evident for the average water condition, because the flow decreased during the measurements, instead of staying constant as in the calculation. Then, the assessment of water concentration can be (held) validated for permanent flow conditions.

\section{CONCLUSION}

Federating in a single tool known models, CASTEAUR have two others original assets, that are its modularity (combination of components, of kind of releases...) and its polyvalency facing fast the operational needs, from crisis to routine situations.

Today formalised as a prototype, the pursuit of the project consists in an intensive validation work on all the code aspects, including mainly numerical solving and assessment quality. In parallel, it would be interesting to tackle uncertainty and variability studies.

\section{References}

[1] Carlier M. Hydraulique générale et appliquée. Eyrolles (Paris, 1980).

[2] Graf W.H., Altinakar M.S. Hydraulique fluviale - tome 1 - Écoulement permanent uniforme et non uniforme. Traité de Génie Civil - Presses Polytechniques et Universitaires romandes, CH-1015 (Lausanne, 1993)

[3] Borovec Z. Element in size-fractionated bottom sediment of the Elbe River in its Czech part. Aquat. Sci. 62 (2000) 232-251.

[4] Krone B.R. Flume studies of the transport of sediment in estuarial shoaling processes, Final report. Hydr. Engr.and San. Engr, Res. Lab, Univ. Calif. (Berkeley,1962).

[5] Amoros C., Petts G.E. Hydrosystèmes fluviaux. Collection d'écologie, Eds MASSON (Paris, Milan, Barcelone, Bonn; 1993).

[6] Boyer P., Deville-Cavelin G., Boullier V., Champelovier A., Gougne C. Dispersion des effluents liquides de la centrale de Civaux - Détermination en conditions réelles de rejet de la zone de bon mélange. Rapport SERE N $^{\circ}$ 7//006 (IPSN, Paris, 1997).

[7] Beaugelin-Seiller K., Adam C., Garnier-Laplace J. Fiche technique : sélection d'un jeu de paramètres radioécologiques associés au prototype CASTEAUR. Rapport SERLAB/00-014 (IPSN, Paris, 2000). 